\title{
Bens publicos, sua alienabilidade e prescriptibilidade.
}

\author{
Terras devolutas, quaes per- \\ tencem aos Municipios, aos \\ Estados e aos particulares. \\ Terrenos urbanos.
}

USUCAPIÃo: - Quando affecta os bens publicos.

Como relator, que fui, na Camara dos Deputados, da parte inicial do Projecto de Codigo Civil, comprehensiva dos seus artigos 79-96, tratando dos "BENS PUBLFCOS", e como autor da actual redacção do art. 67 , posso attestar o pensamento predominante que não destôa do systema geral do Direito, em nada innovou o projecto Bevilaqua, e foi e continua a ser o seguinte.

\section{I}

Bens publicos são os que não pertencem ás pessoas particulares, isto é, ás naturaes e juridicas de direito privado.

O Codigo define:

"Art. 65. - São publicos os bens do dominio nacional, pertencentes á União, aos Estados ou aos Municipios. Todos os outros são particulares, seja qual for a pessoa a que pertençam" 
Em seguida, os classifica:

"Art. 66. - Os bens publicos são:

I. - Os de uso commum do povo, taes como os mares, rios, estradas, ruas e praças.

II. - Os de uso especial, taes como os edificios ou terrenos applicados a serviço ou estabelecimento federal, estadoal ou municipal.

III. - Os dominicaes, isto é, os que constituem o patrimonio da União, dos Estados ou dos Municipios, como objecto de direito pessoal, ou real, de cada uma dessas entidades"

Dessa classificação se vê, para logo, a differença entre bens de uso commum (os quaes, sempre e necessariamente, estão fóra do commercio) e os outros dois, que podem estar no commercio. Essa classificação legal não annulla, nem se oppõe á divisão classica dos bens publicos em duas classes: bens do dominio publico do Estado, e bens do dominio privado do Estado. Applicam-se a nós, no Brasil, os conceitos seguintes: - "L'Etat a deux domaines, le domaine public et le domaine privé. Il importe beaucoup de savoir si un bien appartient au domaine public, ou au domaine privé de l'Etat, puisque, dans le premier cas, il est hors du commerce, tandis que, dans le second, il est alienable et prescreptible" (LAURENT, vol. 6, n. 49). Conferem: PLANIOL, vol. I da 9. edição, pag. 968, e CARLOS DE CARVALHO, Nova Cons. art. $434 \S$ unico.

Portanto, estão fora de commercio sómente os bens do dominio publico do Estado, que o nosso Codigo denomina de "uso commum do povo", pela razão intuitiva de que não é possivel dar a um só individuo, ou a uma associação particular de individuos, o dominio e posse das coisas cujo uso e goso pertencem ao povo inteiro, como: o mar territorial, os rios navegaveis, as estradas reaes, as ruas e praças publicas. Ao passo que as outras duas especies, de uso especial e dominicaes, pertencem ao dominio privado do Estado e são álienaveis, susceptiveis de apropriação individual, estando, ou podendo 
estar, no commercio. O Estado, que os administra e desfructa, pode alienal-os e, na phrase de LAURENT: - "il en jouit et il en peut exclure toute autre personne; il peut aussi l'aliener, tandis le domaine public est hors du commerce"

A triplice classificação feita pelo Codigo só visou esclarecer academicamente, na doutrina, as varias especies de bens publicos.

\section{II}

\section{Alienabilidade ou inalienabilidade}

Não ha texto algum em nosso direito dizendo que os bens publicos são absolutamente inalienaveis. Ao contrario, o art. 67 do Codigo foi escripto para dizer que elles são alienaveis, nos casos e formas que as leis ordinarias prescreverem. Não ha ainda menos na Constituição qualquer principio creador da inalienabilidade dos bens publicos.

O Codigo no art. 67, redigido por mim dispõe:

"Art. 67. - Os bens de que trata o artigo antecedente so perderão a inalienabilidade, que lhes é peculiar, nos casos e fórma que a lei prescrever"

Ora, isso exprime, a não deixar duvida, que quando as leis ordinarias julgarem conveniente poderão alienar quaesquer dos bens publicos, os quaes, portanto, são alienaveis. Por outra: a Nação, exercendo a sua soberania (autoridade irresistivel que, dentro do seu territorio, pode tudo) alienará quando quizer os bens publicos. A inalienabilidade peculiar de que falla o art. 67, é relativa e transitoria; significa sómente que os poderes administrativos da collectividade não podem, por si sós, deliberar e consumar alienações; dependem de lei permissiva, tal como os tutores, curadores e representantes legaes que não podem alienar bens dos representados sem licença judicial. Sempre foi assim.

Não é verdade, como ás vezes se tem escripto entre nós, que os bens de uso commum e os de uso especial sejam abso- 
lutamente inalienaveis. $\mathrm{Nem}$ essas duas especies são inalienaveis, pois que o art. 67 e a realidade dos factos autorisam a alienação de todos os bens publicos, mesmo os de uso commum, estes mediante tratados internacionaes que, approvados pelo Congresso Nacional, são leis obrigatorias.

A razão disso é que os poderes executivos fęderal, estadoal ou municipal, são simples mandatarios do povo, e, como taes, não podem alienar bens sem previos poderes especiaes e expressos emanados dos poderes legislativos. A inalienabilidade, que o art. 67 chama de peculiar, desapparecerá sempre que houver uma lei revogando-a. "Peculiar" não significa: immutavel, irrevogavel; exprime uma qualidade propria, que pode ser dispensada periodicamente por quem a creou, isto é, pelo legislador; a inalienabilidade, como diz Planiol, não attinge tanto á coisa como á pesssoa do proprietario; é uma prohibição a este mais do que uma qualidade da coisa. Note-se que a inalienabilidade só é peculiar, isto é, propria, dos bens de uso commum, pois são os unicos cuja posse é impossivel a uma unica pessoa particular, e são os unicos naturalmente fóra do commercio.

FÓRA DO COMMERCIO é expressão léal do art. 69 do Codigo Civil, a qual deve ser bem comprehendida para evitar erros.

Fóra do commercio significa: $10^{\circ}$ ) as coisas que não podem, por sua natureza, ser objecto de propriedade privada, isto é, que não podem normalmente circular por transmissões arbitrarias e individuaes, e são: as de uso inexhaurivel como o ar, a luz, o mar alto; $2^{\circ}$ ) as coisas publicas de uso commum do povo, como bem especifica Bevilaqua, sem incluir as de uso especial nem as dominicaes (Obs. ao art. 69 na $2 .^{a}$ ed.) e $3 .^{\circ}$ ) as coisas "legalmente inalienaveis", isto é, as que em virtude de lei expressa não podem normal e livremente, mudar de dono, como: Os bens clausulados (arts. 1677 e 1723). Dizemos "normal e livremente" porque a inalienabilidade dos bens fóra do commercio não é absoluta, irreductivel; podem ser alienadas mediante cautelas estabelecidas nas leis, qual se pratica nas subrogações, permutas, etc. 
Diz HAURIOU, Dir. Adm. pag. 664: - "A' l'inverse, les dependences du domaine public redeviennent instantanement aliénables et prescriptibles du jour de la desaffectation; leur mise hors du commerce de la vie privé dure, donc, juste autant que leur affectation"

$\mathrm{E}$, na vida dos povos, desde remota antiguidade, estamos vendo a alienação de bens de uso commum. Ensina PLANIOL: "L'inalienabilité est une consequence naturel et habituel de la dominialité publique, mais elle n'en est point inseparable". LAFAYETTE escreve: "A compra e venda, como modo de cessão de territorios entre as Nações, tem sido usada ainda em tempos recentes"; e sustenta, em seguida, que a prescripção é admissivel entre as Nações como modo de adquirir territorio. (Dir. Int. pag. 153). De facto, é sabido que a França vendeu aos Estados Unidos, por 60.000 .000 de francos a Luiziana; o Principe de Monaco cedeu á França, em 1851, por quatro millhões, os territorios de Menton e Roquebrune; a Inglaterra comprou em 1872 aos Paizes Baixos suas colonias de Guinée; a Hespanha vendeu á Allemanha, em 1899, as ilhas Carolinas e outras, etc. Entre nós ahi está o celebre Tratado de Petropolis em 1903 pelo qual o Brasil permutou (e a permuta é uma alienação) com a Bolivia vastos territorios, permuta essa já prevista e autorisada pelo tratado de 1867 (F Raja Gabaglia, "Fronteiras do Brasil", pag. 277). Vê-se, portanto, que mesmo os bens do dominio publico do Estado podem ser alienados.

Quanto aos da segunda especie, de uso especial, são correntes os exemplos de alienações. Ao acaso encontramos, no Estado de S. Paulo, a recente Lei n. 2122 de 30 de Dezembro de 1926, art. 12, dizendo: - "Fica o Governo autorisado a dispôr pela fórma que julgar conveniente, dos proprios do Estado que não forem necessarios ao serviço publico" (Entre parenthesis, é de notar que nesta lei não é toleravel a infinita amplitude da autorisação para dispor de todos os proprios do Estado. Taes autorisações devem indicar os bens desnecessarios).

E neste momento estamos a ler a noticia seguinte: "Acha-se aberta na Secretaria da Fazenda e do Thesouro do 


\section{$-214-$}

Estado, pelo prazo de 30 dias, uma concorrencia publica para a venda, de accordo com a lei, do predio sito á rua Commendador Luiz Ferreira, na cidade de S. José do Barreiro neste Estado, immovel esse que não tem mais utilidade para o serviço publico". (" O Estado de S. Paulo", e "Correio Paulistano" de 27 de Abril de 1927).

Era melhor a redacção que Bevilaqua havia dado, no art. 81 do projecto primitivo, dizendo: - "Os bens communs, emquanto conservarem esse caracter, não são alienaveis nem sujeitos á usucapião; os de uso especial e os patrimoniaes podem ser alienados de conformidade com as leis que os regulam".

Apezar, porem, da mudança de redacção é facil ver que o sentido do actual art. 67 do Codigo é o mesmo do art. 81 do projecto; tudo que um diz está contido no outro; nada indica, na discussão do projecto, directa ou indirectamente, a intenção de, inconveniente e inscientificamente, mudar-lhe o pensamento. Se mudança tivesse de haver deveria ser expressa. Posso affirmal-o, com segurança, porque fui o autor da actual redacção do art. 67, cujo historico consignamos, adeante, no ultimo capitulo deste estudo.

Quanto aos bens dominicaes é evidente a sua alienabilidade, porque o Codigo os qualifica expressamente como objecto de direito real e pessoal; todos os interpretes estão accordes e os exemplos de alienações são diarios e innumeros. (Vide: Rev. dos Trib. 34, p. 385, e 59, p. 5).

Logo, parece demonstrado, irrespondivelmente, com a lei, a doutrina e a pratica universal, que todos os bens publicos, sem excepção, são alienaveis, mediante maiores ou menores formalidades. Conferem: Ed. Espinola, "Rev. de Crit. Jud.", Rio, vol. de Abril de 1927, pags. 307 e 311; e Dez. Sá Pereira, "Manual do Cod. Civ.", vol. 8 pag. 238. e Specer Vampré "Rev. dos Trib." Vol. 34 pag. 385.

- CLOVIS BEVILAQUA, entretanto, nos seus preciosos Commentarios, tratando do art. 67 do Codigo, no vol. I, da 2." ed. pag. 293, escreveu: - "Tenho por irrecusavel que, em face deste dispositivo, não sendo o usucapião fórma prescripta 
em lei para a alienação dos bens publicos, e não sendo esse um caso especialmente previsto para a perda da inalienabilidade dos bens publicos, estão elles isentos de usucapião. Poderá não ser a melhor doutrina, mas é a da lei".

Surprehende que o brilhante espirito do mestre pudesse deduzir do art. 67 essa peior doutrina, contraria á tradição do direito, como elle proprio o attesta, e destruidora da propriedade privada, que desappareceria quasi toda passando a ser publica, alem de revogar o principio geral do art. $530 \mathrm{n}$. III do Codigo! Basta imaginar que, se assim fosse, somente os bens adquiridos directamente do poder publico teriam titulos firmes de dominio, porque a posse, ainda a mais legitima e longa, jamais daria dominio!.

Pedimos venia para, ligeiramente, objectar contra a sua these, que aliás está rebatida pelo proprio autor, quando na Observação I a esse art. 67, escreve: - "Os bens dominiaes da União, dos Estados e dos Municipios NÃO SÃO INALIENAVEIS, como poderia parecer tomado ao pé da letra o dispositivo do art. 67'.

Eis ahi elle proprio dizendo: "Os bens dominiaes não são inalienaveis"; entretanto, ao commentar o art. 163, diz:"Os bens publicos de qualquer especie, sendo inalienaveis, não podem ser adquiridos por usucapião", A discordancia é visivel.

Que me perdôe o presado amigo, o dispositivo do art. 163 do nosso Codigo dizendo: - "As pessoas juridicas estão sujeitas aos effeitos da prescripção e podem invocal-a sempre que lhes aproveitar", é um principio geral, que se applica á prescripção extinctiva de obrigações, e á prescripção acquisitiva, chamada usucapião. Nem haveria motivo para subordinar as pessoas juridicas (União, Estados e Municipios)á prescripção extinctiva dos seus direitos creditorios e, inexplicavelmente, isental-as da prescripção extinctiva de direitos reaes, quando é certo que sómente a negligencia do titular do direito pessoal ou real fundamenta ambas as prescripções.

Alem disso, seria inconcebivel que o Estado não pudesse adquirir dominio por usucapião, absurdo este que resultaria 
si o principio do art. 163 não fosse applicavel integralmente ás pessoas juridicas de direito publico interno.

Tanto é isto verdade que, por exemplo, o Codigo Civil Chileno, um dos que Bevilaqua cita como legislação comparada, reza no art. 2492: - "La prescripcion es un modo de adquirir las cosas ajenas, o de estinguir las aciones y derechos ajenos", equiparando assim, e muito bem, as duas especies de prescripção; e no art. 2497: - "Las reglas relativas a la prescripcion se aplicam igualmente a favor y contra del Estado, de las iglesias, de las Municipalidades, e de los estabelecimentos y corporaciones nacionales y de los individuos particulares que tienen la libre administracion de lo suyo".

O nosso illustre commentador, na sua Observação n.2 ao art. 67, apresenta como razão da sua these o seguinte argumento: "O usucapião presuppõe um bem capaz de ser livremente alienado".

Ora, com a devida venia, não me parece verdade. Tanto o usucapião não presuppõe um bem capaz de ser livremente alienado que são usucapiveis os bens particulares inalienaveis, taes como os clausulados. Estes, apezar de inalienaveis por acto dos seus donos, são sujeitos ao usucapião, desde que um terceiro os possua em condições de operar a prescripção.

Tambem não me parece verdadeira a sua affirmação seguinte: - "Não sendo o usucapião fórma prescripta em lei para a alienação dos bens publicos". Ora, o usucapião nunca foi, nem será, uma fórma prescripta em lei para alienação.

E' sim um modo, de acquisição de dominio, coisa differente de alienação formal, consciente, bilateral. Nem haveria necessidade de existir um Capitulo especial no Codigo sobre alienação, ou sobre o usucapião, dos bens publicos. Basta a existencia do capitulo II, do titulo II. tratando da "Acquisição da propriedade", no art. 530, n. III. Neste estão comprehendidos todos os bens, particulares e publicos, susceptiveis de posse individual e exclusiva. A alienação normal dos bens publicos se rege pelos principios constitucionaes, que entre nós ñ์ n'a prohibem, $\Theta$ do direito administrativo. 
Finalmente; não procede a razão de que:- "Não é esse um caso especialmente previsto para a perda da inalienabilidade dos bens publicos". Ora, o usucapião jamais será um caso especial para a perda da inalienabilidade de quaesquer bens, publicos ou particulares. A inalienabilidade desapparece automaticamente, porque, existindo em attenção á pessoa do proprietario, cessará desde que o proprietario perca o dominio. Como bem diz Teixeira de Freitas: "a prescripção corre contra todas as pessoas não exceptuadas expressamente por lei" E nenhuma lei nossa exceptua expressamente as pessoas juridicas. Ao contrario, o art. 66, n. III, affirma que os bens dominaes são objecto de direito pessoal ou real, e basta isto para serem usucapiveis; e o art. 163 o confirma claramente.

Si a prescripção extinctiva ou acquisitiva como bem diz Bevilaqua: "constitue uma regra de ordem, de harmonia e de paz imposta pela necessidade da certeza nas relações juridicas; a inercia do titular do direito permitte que se realisem e consolidem factos contrarios ao direito do negligente; destruir esses factos seria perturbar a vida social que sobre elles repouza tranquilla" (Obs. ao art. 163, pag. 424), não se comprehenderia como, contrariamente a taes principios, poderiam a sociedade e os direitos individuaes ser sacrificados para favorecer a inercia dos poderes publicos; dando em resultado, por exemplo, negar dominio a quem tivesse posse mansa, inconteste e continua, sobre um immovel, durante 39 annos, onze mezes e 29 dias, no dia 31 de Dezembro de 1916, vespera do começo da vigencia do nosso Codigo! Seria um confisco, permittido por um Codigo moderno de um povo civilisado, que talvez nem na Russia actual se pratique.

O equivoco do presado commentador provem talvez de haver elle tomado a inalienabilidade como base do usucapião, quando não é, como veremos; e quiçá de haver considerado a expressão "Lei" do art. 67 como devendo existir no Codigo, quando em verdade a expressão "lei" só indica as leis ordinarias 
occasionaes, que a todo tempo vierem a autorisar os poderes executivos a alienar determinados bens publicos, qual tambem veremos adeante.

O caso é tão claro que não comportaria discussão se não fôra a grande autoridade de quem levantou a duvida, a qual já está causando prejuizos e vexações a centenas de proprietarios perfeitamente legitimos, contra os quaes, porem, a cobiça de Camaras Municipaes está movendo reivindicações aventureiras fundadas na opinião respeitavel do illustre commentador.

Porem, como era de esperar da sua sabedoria, consultado, o illustre mestre respondeu como se verá do parecer infra e respectiva consulta, firmando as theses seguintes:

1) - As municipalidades e o Estado não podem reivindicar terras que encontraram possuidas a titulo de dominio por particulares.

2) - A posse de 44 annos desde 1883 até Maio de 1927, (data da consulta) e, portanto, de menos de 40 annos até I de Janeiro de 1917 ( data da vigencia do Cod. Civ.) produz o usucapião em favor do possuidor titulado.

Eis o caso:

Consulta: - F...... é unico dono de uma chacara, n'uma cidade, por titulos regulares de dominio, dos quiaes o mais ántigo tem a data de 4 de Fev. de 1883. Tem até agora posse continua, inconsteste e pacifica, por si e seus antecessores, ha 44 annos. O Estado lhe tem cobrado impostos prediaes e de tramsmissão desse immovel. A Camara Municipal quer reivin dicar esse immovel, allegando que uma lei do Estado de S. Paulo de 13 de Nov. de 1891, fez incluir entre os bens patrimoniaes dos municipios as terras devolutas.

A lei diz.......( transcreve-se a lei).

Pergunta-se:-Em vista do exposto pode a Camara Municipal, reivindicar essa chacara?

S. Paulo, Maio de 1927. 


\section{RESPONDO:}

"Sómente por que uma lei estadual declarou que pertencem á Municipalidade as terras devolutas, em certo perimetro, não está armada de acção reivindicatoria contra o proprietario da chacara, a que se refere a consulta. Ella encontra essas terras possuidas a titulo de dominio, na parte occupada pela chacara: é um titulo concreto, contra o qual não levantou objecções, nem ainda o Estado, para quem as terras devolutas passaram depois da Republica. E' uma situação de direito, que dura ja 44 annos. Seria violencia destruil-a por meio de reivindicatoria. No meu sentir, essa reivindicação somente seria admissivel se a Municipalidade pudesse exhibir titulo concreto de proprietaria, e não uma simples pretensão abstracta.

Rio, 6 de Junho de 1927

\section{(a) Clovis Bevilaqua.}

\section{III}

\section{A prescriptibilidade e imprescriptibilidade}

Mas, da alienabilidade geral dos bens publicos, que acabamos de demonstrar, não se segue que todos elles sejam prescreptiveis, ou usucapiveis.

A prescriptibilidade não se resolve pela alienabilidade, como por irreflexão têm dito alguns interpretes. A questão da alienabilidade, não está ligada á da prescriptibilidade. A chave do problema é outra. Como diz LAURENT:- "L'adage que ce qui est alienable est prescriptible n'est pas exact", (Vol. 32, pag. 230, da 5. ${ }^{\mathrm{a}}$ edi.)

O criterio scientifico, unico a resolver a questão do usucapião, é a theoria legal da posse e da propriedade.

Com effeito, o dominio dos bens publicos, precisamente como o dos bens particulares, é prescriptivel, ou imprescriptivel, conforme forem as condições da sua posse, de accordo com os preceitos do Codigo, arts. 550-553, para os immoveis, e 618-619 para os moveis. 
E' principio banal que a posse sobre bens alheios retirará o dominio do proprietario negligente, transferindo-o para o possuidor titulado e de boa fé, dentro de certo praso, e sem titulo nem boa fé após um praso maior. Tal é o axioma, que domina a prescripção acquisitiva para qualquer especie de bens particulares e tambem para os bens publicos, porque estes não gosam, nesse assumpto, de privilegio algum expresso em lei ou na Constituição.

Logo, todos os bens publicos que, por sua natureza, puderem ser possuidos exclusivamente por alguem, são usucapiveis. Sendo assim, é claro que somente os bens do dominio publico do Estado, que o nosso Codigo denomina de "uso commum do povo", são imprescriptiveis, porque não podem ser possuidos por uma pessoa com exclusão de todas as outras: ninguem pode, realmente, possuir, sósinho, o mar, os rios, as ruas e praças. Dahi se vê que esses bens são imprescriptiveis, não por serem inalienaveis, mas porque são os unicos fóra do commercio, pela sua natureza. (Conferem: o Codigo Civil Francez, arts. 2226 e outros). Mas alem dessa, ha outras razões mais frisantes, se possivel, e são as seguintes:

A) - Os bens de uso commum do povo (mares, rios, estradas, ruas e praças) pertencem ao proprio povo e são possuidos livremente, continuamente, anonymamente, pela collectividade. Como diz Bevilaqua: "são os que pertencem a todos res communes omnium". Todos os individuos componentes do povo são condominos desses bens.

Ora, portanto, não seria possivel, porque seria redundante, a prescripção acquisitiva em favor de quem já édono, e de quem não é, nem pode ser, unico possuidor. A prescripção acquisitiva (usucapião) só opera em favor de um unico possuidor, que exclue os outros.

$\mathrm{Si}$, pois, o possuidor é uma collectividade, nenhum dos seus membros pode possuir por si só. O. uso commum é incompativel com o direito exclusivo de propriedade. Eis porque, repetimos, só os bens de uso commum do povo estão fóra do commercio e só elles são imprescriptiveis. 
B) - Os bens de uso especial (edificios, e terrenos applicados a serviços publicos) não são possuidos ou usados livremente pelo povo. Ninguem pode, quando quizer, entrar e permanecer livremente nos edificios publicos applicados, por exemplo, aos trabalhos ou á residencia dos Chefes do Estado, ou das escolas e outras repartições publicas. A posse de facto reside sempre nos administradores ou occupantes officiaes em nome da collectividade. O povo não tem, por exemplo, as chaves dos quarteis, das fortalezas, dos navios de guerra, dos edificios publicos, etc.

Ora, si os administradores, que são os possuidores e representantes do proprietario, abandonam esses bens a um ou alguns individuos particulares e estes se arvoram claramente em possuidores, como se fossem donos, durante o tempo necessario ao usucapião, adquirirão o dominio perdido pela collectividade. Os administradores desidiosos, ou culposos, que deixaram chegar a esse ponto o abandono do immovel, devem ser responsabilisados como for de lei, (principio este que se vê no art. 164 do Codigo Civil); mas o direito, que o "possuidor adquiriu ao dominio do immovel, deve ser respeitado para cumprimento da lei, isto é, do art. 550 do mesmo codigo que garante os particulares possuidores, sem attenção a quem perdeu o dominio.

Realisa-se nesse caso o usucapião porque o intruso, antes de tomar posse, não tinha a liberdade do uso do edificio; teve-o em consequencia do abandono.

Assim verifica-se que os bens de uso especial são usucapiveis, como os dominicaes. A differença entre os de uso especial e os dominicaes está em que estes ultimos, pela sua condição natural e normal, são sempre usucapiveis qualquer que seja a sua applicação; ao passo que os de uso especial só são usucapiveis a partir do momento em que cessar o uso especial a que eram destinados: Por exemplo: Si um predio, occupado por qualquer repartição publica, é abandonado, fica dahi em deante sujeito á prescrip̧̧ão em favor de quem o possuir. 
O exposto se confirma pelas "Disposíçóes Geraes" do Titulo "Da Prescripção", cujos arts. 161-167 são destinados a regular em geral a prescripção extinctiva e acquisitiva, especialmente os arts. 163 e 164, do nosso Codigo.(*)

\section{IV}

NO DIREITO VELHO os principios eram os mesmos supra expostos.

As coisas do dominio nacional se bipartiam, como hoje, em duas differentes classes: 1) a do dominio publico do Estado, que o Codigo chamou de "uso commum do povo" os quaes estão, naturalmente, fóra do commercio e, por isso, são imprescriptiveis, não sendo susceptiveis de posse exclusiva e individual; e 2) a do dominio privado do Estado, que o Codigo subdividiu em "uso especial".e "dominicaes", e eram terras devolutas, minas, bens do evento e de ausentes, os proprios nacionaes, edificios, palacios, construcções, etc. (T. de Freitas, Cons. arts. 52, 53, 586, $\S \S 11^{\circ}$ e $2 .^{\circ} ;$ e C. de Carvalho, Nova Cons. art. 434॰ $\S$ Un. dizendo: "Os bens do dominio privado da União, dos Estados e dos Municipios são equiparados aos dos particulares".

E quanto ao usucapião: - eram imprescriptiveis, como hoje, somente os bens fóra do commercio, que se resumiam, como hoje, nos de uso commum do povo. Eram prescriptiveis todos os outros bens publicos. (Lafayette, Cousas, $1 .{ }^{\mathrm{a}} \mathrm{ed}$. $\S \S 62$, 65 , n. 4 , e $\S 70$, n. 4. C. de Carvalho, loco supra citado).

Como se vê, o direito anterior ao Codigo não foi modificado, a não ser pela suppressão do praso de 40 annos, como passamos a dizer, prazo esse que, aliás não era de lei, mas sómente um costume, como ensina Lafayette.

\footnotetext{
(*) Sustentam a mesma these os illustres jurisconsultos Eduardo Espinola, na "Rev. de Critica Judiciaria", do Rio, fasciculo de Abril de 1927, pag. 307; e Desembargador Sá Pereira, no "Manual do Cod. Civ." vol. 8, pag. 238; Spencer Vampré, "Man. do Dir. Civ." vol. 2, pag. 87 e "Rev. dos Trib." vol. 34, pag. 385.
} 
$\mathbf{V}$

Tudo quanto acabamos de escrever faz concluir que o Direito Brasileiro, anterior e posterior ao Codigo Civil, era e é o seguinte:

1) Todos os bens do dominio nacional são alienaveis, desde que uma lei o autorise occasionalmente. (Cod.art. 67);

2) São imprescriptiveis, por estarem natural e permanentemente fóra do commercio, somente os bens de "uso commum do povo" (art. 66, n. 1);

3) São prescriptiveis os bens de "uso especial", desde o momento em que, cessando a sua applicação a serviços ou estabelecimentos publicos, forem possuidos por pessoas particulares (art. 66. n. II);

4) São sempre prescriptiveis, qualquer que seja a sua applicação e desde que sejam possuidos por terceiros, os bens "dominicaes" (art. 66, n. .III);

5) A prescripção contra os immoveis publicos de uso especial e dominicaes realisa-se pela posse ininterrupta e inconteste de terceiros durante 10 annos entre presentes ou 20 annos entre ausentes, tendo o possuidor justo titulo e boa fé (art. 551); e durante 30 annos, independentemente de titulo e boa fé (art. 550). Quanto aos bens moveis realisa-se o usucapião nos termos dos arts. 618 e 619 ;

6). Reduzido, como foi pelo Codigo Civil, o prazo extraordiario de 40 annos de que, não por lei mas por simples costume, gozava o Estado, os seus bens do dominio privado prescrevem após 30 annos, sem tiulo, nem boa fé.

Com effeito, o Codigo rege os casos não manifestados em juizo antes da sua vigencia, porque o Estado não tinha ainda um direito adquirido. Como se sabe, a irretroactividade das leis não é um phenomeno cego e absoluto que mantenha inabalavelmente todas as situações anteriores, o que conduziria a absurdos.

A simples faculdade, ou capacidade de propor em juizo a acção de reivindicação, dentro do praso de quarenta annos, 
não era um direito adquirido, porque só estaria no patrimonio do reivindicante si elle houvesse iniciado a acção em juizo antes de entrar em vigor o Codigo. (Rev. dos Trib. Vol. 28, pag. 69).

$O$ direito adquirido, (que não se confunde com o direito já consummado) ensina GABBA, é toda a consequencia legitima de um FACTO occorrido de accordo com a lei, mas ainda não executada. Ora, esse "FACTO" não é a simples vigencia de uma lei nova, porque, se fosse, jamais esta teria applicação ás pessoas existentes ao tempo da lei velha, o que seria um dislate. FACTO é o acontecimento occorrido, o acto praticado, ou a acção começada praticamente a ser exercida. Por isso, a aç̧ão judicial começada constitue um direito que $o$ autor adquiriu para obter a applicação da lei em cuja vigencia iniciou a aç̧ão. O facto da acção judicial é que dará começo, ou existencia, á relação de direito, como diz C. Carvalho.

A relação de direito nasce com o facto da propositura da acçạ̃o em juizo; mas não com a simples existencia platonica, ou latente, da lei.

O Codigo foi promulgado em 1 de Janeiro de 1916; desde então fez-se conhecido para prevenir aos interessados das modificações introduzidas no Direito Civil. Mas, só entrou em vigor um anno depois, em 1 de Janeiro de 1917, como se vê do seu art. 1806.

$\mathrm{Si}$, pois, nesse longo periodo de prevenção o Estado não quiz iniciar as acções de reivindicação, a que tivesse legitimo direito, signal é de que se subordinou conscientemente á lei nova, permittindo que os possuidores, sem titulo nem boa fé, adquirissem o dominio após trinta annos de posse inconteste, na fórma do Codigo, art. 550, combinado com os arts. 163, 172 n. I; $177,179,1806,1807$ e outros.

Cogitando precisamente da hypothese, ensina PLANIOL: - "Supposons que la prescription nécessaire pour acquerir la proprieté immobilière soit ramenée de 30 á 15 ans. La loi nouvelle sera rétroactive pour toutes les possessions ayant déjà 
plus de 15 ans d'existence, si on l'applique purement et simplement, car elle attibuera une consequence juridique (l'acquisition de la proprieté) á un fait (la durée d'une possession superieure á quinze ans) qui s'est passé entièrement sous l'empire de la loi anterieure" (Vol, I. pag 94).

Tambem os notaveis civilistas COLIN et CAPITAN doutrinam:

"De même encore, une loi qui modifie les règles admises antérieurment pour la prescription, par exemple, en reculant le point de départ, s'applique immediatement aux prescriptions en cours au moment où elle est promulguée" (Cours Elementaire de Droit Civil, Vol. I, pag. 51 da $4 .^{a}$ edic.)

E o Codigo Francez no art. 2281 contem o seguinte:"Néanmoins les prescriptions alors commencées, et pour lesquelles il faudrait encore, suivant les anciennes lois, plus de trente ans à compter de la même époque, seront accomplis par ce laps de trente ans",

O nosso direito nesse particular não é differente do francez, cujo Codigo Civil, art. 2, consigna o principio da irretroactividade das leis, que a nossa Constituição consagra.

Portanto, em face das leis, da doutrina e do bom senso, si a União, os Estados e os Municipios, sabiam desde 1 de Janeiro de 1916, data do Codigo Civil, que um anno depois, em 1 de Janeiro de 1917, seria reduzido a 30 annos o praso de 40 , para reivindicar bens seus illegitimamente possuidos por terceiros, e não iniciaram em juizo as respectivas reivindicações, subordinaram-se conscientemente á lei nova, sem.poder allegar a sua ignorancia pois que estava publicada.

Se assim não fosse, teriamos o absurdo seguinte: todos os prasos e todos os direitos e todas as faculdades da leis velhas continuariam vigorando para toda a gente que tivesse começado a viver antes do Codigo. Não vae até lá a irretroactividade das leis! 


\section{VI \\ Terras devolutas e terrenos urbanos}

"DEVOLUTA" significa, na lingua portugueza, uma coisa VAGA, DESOCCUPADA (Moraes, e Caldas Aulete), VAZIA (Roquete).

DEVOLUTAS, portanto, são as terras desoccupadas, disponiveis, vazias, sem detentor.

Entre nós a palavra devoluta foi empregada para exprimir as terras desoccupadas, originariamente constitutivas do territorio publico da Nação. A Lei de 15 de Novembro de 1831, art. 51, § 15, mandou arrendar em hasta publica, a prazos e por lotes, os terrenos desnecessarios aos serviços publicos. A lei de 12 de Outubro de 1833 deu providencias quanto ás fabricas, terrenos e proprios nacionaes. O Aviso de $16 \mathrm{de}$ Março de 1847 declarou que os "terrenos devolutos" do Imperio, não se devem dar em arrendamento.

Por consenso e costume geral eram occupadas essas terras pelos particulares, os quaes, pelo unico facto da occupação, tornavam-se donos. O direito costumeiro creou assim uma especie singular de ńsucapião immediato, decorrente da posse, qualquer que fosse a sua duração.

Justificava-se isso pela conveniencia, que tinha o paiz nascente e despovoado, de favorecer e garantir o trabalho, a produç̧ão e o povoamento rapido. Bastava, pois, occupar terras publicas para, desde logo, adquirir-lhes gratuitamente o dominio. E assim se formou no Estado de São Paulo, a sua enorme riqueza e fecunda agricultura. Até 1850 foi essa a realidade de facto e de direito. E não admira que assim fosse porque hoje, um seculo depois, ainda se admitte semelhante criterio no Estado de São Paulo, cuja recente Lei n. 1844 de 27 de Dez. de 1921, art. 4, dispõe: "Fica a Governo autorisado a conceder titulo de dominio:

b) a todo o possuidor de terras devolutas que as tiver obtido por titulo NÃO LEGITIMO anterior a esta lei". 
Mas, como era natural, a Nação julgou opportuno, em 1850, regular a situação dos possuidores; e principalmente auferir vantagens vendendo, aforando ou arrendando as terras "devolutas" E sem modificar jamais os principios do direito civil, relativamente á acquisição da propriedade e sem violencias ou confiscos á posse privada, decretou a celebre LEI n. 601 de 18 de Set. de 1850 e o seu Reg. n. 1318 de 30 de Janeiro de 1854 . E então a citada Lei de 1850 determinou, como intuito primordial assim:

\section{Art. 1. - "Ficam prohibidas as acquisições de terras devolutas por outro titulo que não seja o de compra"}

Isso exprime que antes da lei de 1850 a simples posse, de qualquer duração, pelo direito costumeiro, era titulo de dominio; e que pelo direito positivo a posse trintennaria, sem titulo nem boa fé, tambem e com maior razão, produzia a prescripção acquisitiva em favor do possuidor. O exposto se confirma no Reg. citado de 1854, dizendo no

Art. 20 - "As posses estabelecidas depois da publicação do presente Regulamento não devem ser respeitadas"

A contrario senso, quer dizer que as posses anteriores ao Regulamento deviam ser respeitadas.

Visto assim o fim principal da Lei de 1850 , vejamos como ella definiu o que seja terra devoluta:

Art. 3.- "São terras devolutas:

$\S 10^{\circ}$ - As que NÃO se acharem no dominio particular por QUALQUER TITULO LEGITIMO, nem forem havidas por sesmarias e outras concessões do Governo, não incursas em commisso. $\S 2 .^{\circ}-$ As que NÃO se acharem dadas por sesmarias, ou outras concessões do Governo, que apezar de incursas em commisso, forem revalidadas por esta lei.

$\S 3 .^{\circ}-$ As que NÃO se acharem occupadas por posses que apezar de não se fundarem em 
titulo legal, forem legitimadas por esta lei" (Confere a Consolidação, feita por T. de Freitas, art. 53).

E' clarissimo, portanto, que as terras devolutas são as vazias, desoccupadas, porque são as:

a) NÃO applicadas a uso publico;

b) NÃO estiverem no dominio particular por QUALQUER TITULO LEGITIMO;

c) NÃO forem adquiridas por concessão do Governo; madas:

d) NÃO forem occupadas por posses legiti-

Sempre a NEGATIVA: de uso publico ou de acquisição por QUALQUER TITULO, portanto, por USUCAPIÃO, que era um titulo legitimo de acquisição de dominio.

Isto se repete expressamente no Regulamento n. 1318 de 1854, dizendo no:

Art. 22 . - "O disposto no $\S .2 .^{\circ}$ do art. 3 da Lei n. 601 de 1850 exclue do dominio publico e considera como não devolutas todas as terras que se acharem no dominio particular por QUALQUER TITULO LEGITIMO"

$\mathrm{E}$, mais, no:

Art. 23. - "Estes possuidores não têm precisão de revalidação, nem de legitimação, nem de novos titulos para poderem fazer hypothecar ou alienar as terras que se acham no seu DOMINIO"

Seria pueril e indouto pensar que "titulo legitimo" seja sempre uma escriptura, papel, ou formal, de posse. Quando a lei fallou em "QUALQUER TITULO LEGITIMO" fel-o com a significação juridica. E para cortar duvidas o seu Regulamento, no art. 25, definiu:- "São titulos legitimos todos aquelles que, segundo direito, são aptos-para transferir o dominio". Confere Lafayette dizendo: "Os modos de adquirir são:. prescripção acquisitiva” (Cousas, § 32). 
Conseguintemente, a Lei de 1850 não modificou o Direito Civil quanto á prescripção acquisitiva. De maneira que, antes e depois dessa lei, continuou a ser titulo legitimo de dominio a posse capaz de produzir o usucapião.

$O$ que a Lei de 1850 aboliu foi a acquisição gratuita e immediata do dominio, pela posse de tempo inferior ao exigido pelo direito commum para operar a acquisição do dominio. E' o que se vê de toda a legislação do Imperio, inclusive os innumeros Avisos, cujo fim principal foi proporcionar remuneração ao Thesouro Nacional pelos aforamentos e vendas de terras, cujas concessões gratuitas ficaram, em geral, prohibidas como dizia o Aviso de 24 de Março de 1851, só cabendo ao poder legislativo, qual o disse o Aviso de 6 de Set. de 1859.

Portanto, todo o possuidor que tivesse posse trintannaria, capaz de operar, por si só, o usucapião, sem titulo nem boa fé, tornava-se dono, sem necessidade de legitimação e revalidação.

O exposto, que decorre das leis, está confirmado pela lição do douto Macedo Soares no seu notavel livro "Tratado da Medição e demarcação das terras", edição de 1878, nota a pag. 115, dizendo: "A prescrip̧̧̃̃o trintannaria é um titulo, pois dispensa a exhibição de qualquer outro e comprehende-se no numero dos titulos legitimos definidos pelo art. 25 do Reg. de 1854 e que o art. 22 manda respeitar. $O$ segundo occupante, possuindo por mais de trinta annos (e pode utilisar a posse de boa fé do primeiro), mesmo sem compra, tem na prescrip̧̧̃̃o um titulo legitimo que o colloca ao abrigo da Lei. $O$ art. 22 do Reg. diz; "a lei considera como não devolutas todas as tęrras que se acharem no dominio particular por qualquer titulo legitimo"; e a prescripção trintannaria não é só um modo, é um titulo de adquisição do dominio: Mello Freire, liv. 3, tit. 4, § I; Correia Telles, Dig. I, n. 1342" Essa lição de Macedo Soares é repetida, noutros termos, por LAFAYETTE, (Cousas, § 62) quando no capitulo "Direitos 
e cousas prescriptiveis em geral" diz: "Não entram nesta classe (fóra do commercio) e PODEM SER PRESCRIPTAS as cousas do dominio do Estado, isto é, aquellas acerca das quaes o Estado + é considerado como simples proprietario, taes como; as terras devolutas".

E em sua nota 2 á pag. 175 accrescenta: "Assim os bens do dominio do Estado, das municipalidades e das igrejas só podem ser adquiridos pela prescripção extraordinaria, a qual dispensa o requisito do ju sto titulo". E no $\S 70$, pag. 187: "A prescripşão extraordinaria requer, como a ordinaria e nos mesmos termos, a posse e a boa fé, mas dispensa o justo titulo. A longa duração da posse é, no conceito da lei, sufficiente para cobrir aquella falta. Esta especie de prescripção só se con summa no espaço de trinta annos. Mas, por excepção, só podem ser prescriptos em quarenta annos os bens do dominio do Estado, cidades, villas" "E accresenta, em nota, que os 40 annos não eram de lei, mas uma opinião geralmente seguida.

Logo, é indiscutivel que, no regimen da Lei de 1850, a posse longa, por si só, sem mais qualquer outra formalidade administrativa, fazia, como hoje, adquirir o dominio, pois era titulo legitimo.

O que a Lei de 1850 p rohibiu foi a simples occupação, que é coisa differente de posse juridica, ou como diz Carlos de Carvalho, "Nova Cons." no Capitulo "Da Occupação e da accessão", art. 416: - "As terras publicas não podem mais ser adquiridas por occupação pelos particulares" Mas, no Capitulo "Da Prescripção" art. 431, § Unico, diz:- "O praso de 40 annos é exigido para a prescripşão dos bens do dominio privado da União"; abrangendo, portanto, as terras devolutas, que incontestavelmente são bens do dominio privado do Estado.

Tal era o direito brasileiro no Imperio.

Vejamos na Republica.

A Constituição Federal disse no:

Art. 64 - "Perten cem aos Estados as minas e terras devolutas situadas nos seus territorios, ca- 
bendo á União somente a porção de territorio indispensavel para a defesa das fronteiras, construcções militares e estradas de ferro federaes"

Este dispositivo, que dispensa commentarios, deixa claro que as terras devolutas, são sómente as desoccupadas, as quaes passaram ao dominio dos Estados.

Isto se confirma no importante Aviso n. 3 de 23 de Julho de 1901, no qual o Ministerio da Fazẹnda da União, interpretando o art. 64 da Constituição federal, explicou:

"Das disposições do art. 3 e seus $\S \S$ do Dec. n. 601 de 18 de Set. de 1850 e Leis. claramente se comprehende que! como terras devolutas devem se considerar tão somente aquellas sobre as quaes JAMAIS se exerceu o direito de posse ou de propriedade. A estas é que, EVIDENTEMENTE, se refere o citado art. 64 da Constituição" ("O DIREITO", vol. 86, pag. 141).

O Estado de S. Paulo, na sua Constituição, art. 24, n. 18, letra n), deu ao Congresso legislativo a attribuição de legislar sobre "terras devolutas, terras publicas, rios publicos do Estado e minas situadas no seu territorio" Vê-se ahi a distinção entre terras devolutas e terras publicas, para mostrar que as primeiras são as disponiveis, sobre as, quaes não houver qualquer occupação de particulares.

O Estado, pela sua Lei, organica dos municipios, partilhou com estes as terras devolutas, decretando:

"A receita dos municipios será constituida sómente das seguintes verbas:

1. - - Da alienação, aforamento e locação de moveis e immoveis do dominio privado das municipalidades, comprehendidas as terras devolutas adjacentes ás povoações de mais de mil almas, no raio do circulo de seis kilometros, a partir da praça central. 
Este perimetro será marcado á custa dos municipios, com especificação da area dos baldios para lougradouros (Lei n. 16 de 13 de Nov. de 1891, art. 38, n. I, e Lei n. 1038 de 19 de Dez. de 1906, art. 19, n. I).

Data d'ahi o titulo de dominio dos Municipios, que cederá, entretanto, a titulos anteriores dos particulares, como já decidiu muito bem o Tribunal de S. Paulo, dizendo: "O facto de estar o terreno dentro dos limites da concessão, feita aos municipios pelo art. 38 da lei de 13 de novembro de 1891, não aproveita á embargante (Camara municipal), porque a concessão se refere a terrenos devolutos, e antes dessa data já estava o terreno no dominio particular. Em falta de justo titulo não prevalece a prescripção acquisitiva ordinaria de 20 annos, invocada pela embargante; e para a prescripção extraordinaria falta o requisito da posse de 30 annos. S. Paulo, 9 de Fevereiro de 1917. - Xavier de Toledo. P. - Moretz Sohn. - F. Saldanha. - Urbano Marcondes. - M. Mello Junior. - Octaviano Vieira" (Rev. dos Trib. vol 21, pag. 71).

\section{VII}

\section{Terras dos Municipios}

Mas, onde estão localisadas as terras, cabentes aos municipios? E' esta uma preliminar interessante, a ser resolvida.

Para fixar com exactidão scientifica, recorremos á competencia do illustre e respeitavel, Dr. F. P. RAMOS DE AZEVEDO, Director e Professor da Escola Politechnica, fazendothe a seguinte consulta, á qual elle responde como se vae ver:

\section{"CONSULTA:}

"Tendo em vista a phrase seguinte: - "terras devulutas ADJACENTES ás povoações de mais de mil almas, no raio do circulo de seis kilometros, a partir da praça central", 


\section{Pergunta-se:}

$1 .^{\circ}$ - Que se deve entender por "ADJACENTES" ? Serão as terras dentro do perimetro das povoações, ou fóra desse perimetro?

RESPOSTA : - São as terras contiguas, jacentes ao pé das que são limitadas pela linha do perimetro traçado, e alem da superficie delimitada pelo mesmo, consequentemente fóra delle.

$2 .^{\circ}$ - Que se déve entender pela expressão: raio do circulo de 6 kilometros a 'partir da praça central?

RESPOSTA: - A distancia do centro'á cada um dos pontos cuja successão fórma a circumferencia da delimitação do circulo.

$3 .^{\circ}$ - Qual é a praça central de S. Paulo?

RESPOSTA: - Convencionalmente a praça da. Cathedral.

S. Paulo, 11 de Maio de 1927

(assignado) F. P. RAMOS DE AZEVEDO"

Não podia ser outra a resposta, para quem conhece as sciencias phisico-geometricas e a lingua portugueza; pois tudo quanto é ADJACENTE não pode ser interno, ou estar dentro; ha de ser contiguo, confinante, externo.

A palavra "adjacente", é composta do prefixo latino "ad", que, referindo-se a movimento, exprime: "fim ou final do movimento", e do adjectivo "jacente", que significa situado. Logo, adjacente quer dizer: situado no fim, para fóra, e nunea para dentro. R. Pombo, no Dicc. de sinonimos ensina: "contiguo, vizinho, proximo, confim, confinante, limitrophe, immediato unido.» Tão banal é o significado, que será inadmissivel suppor que o legislador o não conhecesse. Seria muito facil dizer: "dentro das povoações", ou "nas povoações" se o legislador assim quizesse exprimir o seu pensamento. E' como a palavra "advindo", que significa: vir depois, accres- 
cer, sobrevir. A liberdade dos interpretes não vae ao ponto de suppor o contrario do que significam os vocabulos

A phrase immediata: "No raio do circulo de 6 kilometros", não pode modificar a força da palavra "ADJACENTE"; nem mesmo se refere a ella. Exprime apenas que as pọvoações devem dispor da superficie limitada por um circulo, cujo raio deve ter seis kilometros. $O$ texto, emfim, se decompõe assim:

$\left.1 .^{\circ}\right)$ as terras devolutas estão adjacentes ás povoações de mais de mil almas;

$\left.2^{\circ}\right)$ as povoações, para esse effeito, serão limitadas por um circulo formado pelos raios de 6 kilometros, a partir da praça central existente.

Nem pode deixar de ser assim, porque em 1891, ao decretar essa lei, o legislador paulista sabia que, no Estado de S. Paulo, dentro de qualquer povoação superior a mil almas, raramente existiam terras devolutas, pois estavam no dominio ou na posse dos particulares, ou das Parochias ou Egrejas, ou do Estado pelos seus edificios: cadeias, escolas, Forums, etc., ou do Municipio pelos terrenos possuidos e occupados pelas ruas, praças, jardins, mercados, mananciaes, casas das Camaras, cemiterios, etc., etc. Assim, na capital de S. Paulo, por exemplo, a municipalidade sempre possuio terrenos utilisados e occupados por serviços e estabelecimentos municipaes, chegando, em certa epoca a dar ou vender as chamadas "DATAS", ou lotes de terrenos, que ella havia adquirido por varios titulos, inclusivé concessão do Governo Imperial. A sua posse continua sempre foi respeitada. Seria, portanto, um presente negativo e ridiculo se as leis de 1891 e de 1906 se tivessem referido aos terrenos urbanos devolutos, inexistentes!

O Estado quiz beneficiar aos municipios, e ao mesmo tempo, commetter-lhes o encargo de cuidar do povoamento, da agricultura, emfim do desenvolvimento das terras desoccupadas fóra das povoações. Isso era bem comprehensivel no inicio da Republica, quando sonhava-se com a autonomia municipal. Era natural que os municipios, sendo bem governados; e mais em contacto com as zonas inhabitadas, fossem mais 
aptos a administrar essas partes do territorio do Estado, afastadas do centro da administração.

Não é possivel aos municipios pretender terras dentro, e ao meśmo tempo, fóra das povoações. Ou uma coisa ou outra; ou dentro ou fóra. $\mathrm{E}$ pois que não ha terras devolutas dentro das povoações, só podem ser as de fóra.

Seja boa ou má a phrase legal, leve a quaesquer conclusões, é evidente que o legislador estadoal quiz dar aos municipios sómente as terras que, naquella occasião, estavam desoccupadas pelos predios, quintaes, jardins, chacaras, cercas, fechos, emfim que constituiam o povoamento, manifestado pelo trabalho, ou uso do homem, com habitação, ou com simples detenção. Favorecia assim, sem cobiças, e mui sabiamente, a formação das cidades.

Não quiz o legislador expulsar ninguem dos terrenos urbanos, o que seria impolitico e brutal, maximé no começo de um regimen novo como a Republica, e num paiz onde o principal problema é o povoamento.

Nem seria honesto da parte do poder publico. Portanto, o espirito da lei, consoante ao Direito commum que nos regia e nos rege, foi o de respeitar as posses das cidades, existentes em 1891, salvos os direitos de terceiros. Entre os particulares podia e pode haver disputas de dominio, mas nunca o poder publico, sem ter posse propria e material, poderá retirar dos particulares aquillo que estes possuiam pacificamente e de boa fé. Seria indecoroso no Brasil que o poder publico exigisse dos particulares uma prova, chamada «diabolica» pelos antigos interpretes, (Laurent, Vol. 6, pag. 216), que é sempre difficil e muita vez impossivel, de posse longuissima; sabido que os nosso costumes e conveniencias sempre foram no sentido de facilitar ao povo a acquisição de terras para povoamento do vasto paiz.

Para evitar as posses provadamente de má fé a Municipalidade e o Estado tinham o dever de demarcar e caracterisar rigorosamente suas terras desoccupadas como resulta expressamente das citadas leis paulistas de 1891, art. 38, n. I, e de 1906, art. 19. n. I, quando disseram: "Este perimetro 
SERA' MARCADO á custa dos Municipios, com especificação da area dos baldios para lougradores publicos, os quaes serão inalienaveis".

Sempre foi isso recommendado pelas leis, inclusive a de n. 601 de 1850 e seu Reg. de 1854; o importante Aviso n. 98 de 8 de Maio de 1854 , art. $1 .^{\circ}$ creou, em cada districto, um Inspector Geral encarregado de medir, demarcar e descrever as terras devolutas. Mesmo a lei de $1 .^{\circ}$ de Out. de 1828 , organica dos Municipios do Imperio, indirectamente; aconselhava a demarcação, necessaria á "descripção topographica" e aos "tombamentos" de que cogitavam os seus arts. 42 e 51 .

Isto foi repetido, mais incisivamente, sendo dado aos municipios o praso de tres annos para demarcarem, sob pena de commisso, pelo Dec. estadoal n. 734 de 5 de Janeiro de 1900, art. 222 .

Essa recommendação legal tinha principalmente por fim effectivar a posse da Camara, difficultando que os intrusos, sem titulo, a tomassem antes da Camara.

Tal demarcação constituiria o titulo concreto, que completaria o acto da doação abstracta.

Sem demarcação e sem transcripção, como realisar e provar a tradição da coisa doada? E sem tradição não ha acquisição do dominio.

$\mathrm{O}$ decr. n. 734, portanto, regulamentando leis anteriores, não exhorbitou nesse ponto; ao contrario, traçou um modo pratico de executar as leis.

Mas, quande tivesse exhorbitado, existem as leis n. 16 de 1891, art. 38 e n. 1038 de 1906, art. 19, mandando marcar, ou demarcar. Si estas leis não fallavam em pena de commisso entretanto, tal pena decorre naturalmente da infraç̧ão, segundo o direito das Obrigações; e incontestavelmente a falta da demarcação torna melhor e mais velha a posse dos particulares sobre terras jamais possuidas pela Camara. Dahi se vê que era do interesse e do dever da propria donataria fazer a demarcação, ainda que a lei o não ordenasse, porque 
"o negligente em zelar, como bom pae de familia, pela integridade do seu predio, sibi imputet; não tem a quem lançar as consequencias da sua incuria"

Sem demarcą̧ão não é possivel reivindicar, razão pela qual não é possivel reivindicar coisa pro indiviso, como bem decidiu o Supremo Tribunal Federal ${ }_{2}$ entre outros, no Accordam que julgou:

são carecedores da acção de reivindicação os condominos de um immovel indiviso e commum, nos termos da Ord. Liv. 3, tit. 53, prine" (REV DO SUPREMO TRIB. Vol. 29, pag. 138, e outros).

Ora, as terras devolutas da Camara estarão em commum emquanto não forem demarcadas.

E o nosso Tribunal Paulista tambem ja tem firmado que:

A acção de reivindicação é impropria para rehaver terras invadidas por terceiros, porque a determinação dessas terras só pode ser feita por aç̧ão de demarcação" (REV. DOS TRIB. Vol. 7, pag. 302, e Vol. 22, pag. 192, e outros.)

Sem demarcação não é possivel estabelecer a identidade situação, limites certos; e outras individuações da coisa a reivindicar.

Demarcação é o acto de estremar, abalisar limites e confins de terras. (Per. e Souza).

Ora não o tendo feito, regularmente, e com a publicidade necessaria, desde 1891 (ha 36 annos) não é justo, nem juridico, que após tanta inercia, ou por causa dessa inercia, venham a pretender reivindicações contra quem, de boa fé, que sempre se presume, adquiriu publica e pacificamente o dominio pelo usucapião, confiante no direito e no costume immemorial do Brasil; ou como diz Lafayette: "pelo que tem visto e ouvido de seus maiores"; concorrendo tambem para a circulação, riqueza e tambem para o augmento das rendas publicas. Ao contrario chegariamos ao absurdo de eliminar a propriedade privada, sem a qual, aliás não ha rendas publicas. 


\section{TRANSCRIPÇÃO NO REGISTRO GERAL}

Accresce notar um outro motivo para essa demarcação

ou "marcação" exigida, sabiamente, pelas leis organicas dos municipios paulistas,.

E' que só após a demarcação de cada gleba, teriam as municipalidades titulos concretos, para serem transcriptos no Registro Geral. Não basta que as leis abstractamente attribuam dominio aos Estados, como fez a Const. no art. 64, ou aos municipios, como fez a lei organica de 1891. Essa concessão precisa de ser materialisada em titulos, que as demarcações fornecem, para serem registrados; só assim consumar-se-á a acquisição do dominio, na fórma dos preceitos absolutos do Cod. Civ. art. 530, n. I, 531, 532, n. 1 e 533, já anteriormente consagrados pelo nosso direito. (Lafayette, "Cousas, Vol. 1, §. $\S 43,48$, dizendo á pag. 134 da I ${ }^{a}$ ed.: - “O adquirente, emquanto não trascreve o seu titulo, não pode reivindical-o, do poder de quem o detenha, com ou sem titulo, em boa ou má fé")

O unico meio de classificar o dominio, estabelecendo a preferencia entre os disputantes, é o numero de ordem do Registro realisado. Os poderes publicos, Estados ou Municipios, não estão isentos dessa solennidade essencial a quaesquer acquisições de immoveis, ainda que decorrentes de leis. A doação, que a lei do Estado fez aos municipios, das terras devolutas, estava e está, hoje mais do que nunca, subordinada á transcripşão de cada parcella, ou gleba de terras que for demarcada sem offensa de direitos de terceiros. De outro modo não é possivel resalvar direitos dos municipios em conflicto com particulares, ou vice-versa.

\section{VIII}

\section{Terrenos urbanos}

$\mathrm{Na}$ expressão "terras devolutas" não se comprehendem os terrenos urbanos, constitutivos das povoações.

A palavra "terras" exprime, na linguagem tradicional do povo e das leis do Brasil, uma porção maior, constitutiva das 
herdades, fazendas, sesmarias, sitios, emfim propriedades rusticas; ao passo que os terrenos são areas menores, de habitação nas cidades, villas ou povoações, "dentro das quaes é cobrado o imposto predial", como diz, por exemplo, o Dec. n. 178 de 29 de Abril de 1893, art. 186. Ninguem dirá: "Comprei terras, a tanto por metro, na Rua Direita, ou na Avenida Paulista"

Assim:

- A lei n. 514 de 2 de Out. de 1848, art. 16 escreve:- "concede ás provincias seis leguas em quadra de terras devolutas exclusivamente destinadas á colonisação"

- A lei n. 601 de 18 de Setembro de 1850, no art. 2, caracterisa as terras devolutas como sendo onde "derrubarem mattos"; no art. 4: - "que se acharem cultivadas"; no $\$ 1$ : "campos de criação ou pastagem"; no art. 12: "as que o Governo reservasse para a fundação de povoações" (o que exclue as já fundadas), etc., etc.

Todas as leis do Imperio e da Republica deixam ver que cogitavam das terras ruraes ou suburbanas. Esse é o sentido. do art. 64 da Const. Federal.

No Estado de São Paulo foi mantida essa tradição, quando, desde a sua primeira lei organica dos municipios, n. 16 de 1891, art. 38, fallou em "terras devolutas" E, legislando sobre ellas, o Estado excluio, implicitamente, do dominio publico os terrenos urbanos já na posse dos particulares. E é justo e conveniente.

Com effeito, a lei paulista n. 323 de 22 de Junho de 1895, art. $3, \S 2$, reservando terras (vazias) para a fundaşão de futuras povoações, ipso facto excluio as povoações já existentes; no art. 5, $\S 3$ falla em: "terras virgens, mattas, campos para creação e lotes suburbanos"; e os arts. 9, 10 e todos os outros fazem perceber que a unica preoccupação do legislador foram as terras ruraes. O mesmo se vê no Reg. n. 734 de 5 de Janeiro de 1900 , art. $30, \S 3$ e art. 222 , este ultimo, muito importante porque faz cahir em commisso as terras devolutas 
que, no praso de tres annos, não forem demarcadas pelas municipalidade.

De modo que os terrenos urbanos sempre foram considerados, pelas leis e consenso geral, como pertencentes aos.possuidores, titulados ou não, sejam pessoas particulares, sejam pessoas juridicas de direito publico interno, e salvas as preferencias entre ellas, decorrentes do direito commum. De tal arte, as posses materiaes dos poderes publicos, com effectiva actuação physica, caracterisadas por obras, marcos, signaes, edificios, estabelecimentos ou serviços, concorrem com as posses dos particulares. $\mathrm{Ou}$, melhor: em relação aos terrenos urbanos, os poderes publicos, si forem possuidores de facto, podem invocar a seu favor a prescripção acquisitiva fundada na posse material, consoante ao direito civil, para excluir a todos quantos não tiverem posse melhor. (Cod. Civ. arts. 163, 530, n. III e 550-553). O que não podem os poderes publicos, União, Estados ou Municipios, é allegar um dominio eterno, noli me tangere, para, não obstante o abandono indefinido, prejudicar o direito adquirido pelos particulares, que tiverem posse capaz de operar o usucapião. Todos, particulares e poderes publicos, 'estão regidos pelo direito civil vigente, em materia de propriedade

Não é, portanto, nem civil nem constitucional, nem logico, nem politico, ou siquer decente que o poder publico fique inactivo, sem praticar actos possessorios ostensivos, sem demarcação que lhes forneça titulos a registrar, contemplando o trabalho dos particulares, a formação e augmento das povoações, cobrando impostos, dando alinhamento e autorisando cercas e muros, e depois de tudo isso, decorridos 10, 20 ou 30 annos, confisque a propriedade privada, expulse os possuidores, e reivindique os bens alheios, arrogando-se um privilegio que só nos tempos feudaes seria realisavel, mas não dignificante.

\section{EM RESUMO:}

1..$^{\circ}$ - Passaram ao dominio dos Estados as "terras devolutas" (ruraes e suburbanas), que estavam desoccupadas 
no inicio da vigencia da Constituição Federal, ex-vi do seu ant. 64 .

2. ${ }^{\circ}$ - Passaram aos Municipios paulistas, desde 1891, das referidas terras devolutas (desoccupadas) as ADJACENTES (contiguas) ás povoações que tiverem mais de mil almas. Para esse effeito, será considerada como povoação uma area delimitada por um circulo, cujo raio medirá 6 kilometros a partir da praça central existente. (Lei paulistas n. 16 de 1891, art. 38 e n. 1038 de 1906, art. 19).

$\left.3 .^{\circ}\right)$ - Os municipios, entretanto, perderam o direito a taes terras, mesmo desoccupadas, si não as demarcaram e principalmente se munidos de titulos concretos deccorrentes das demarcações, não os fizeram transcrever no Registro Geral para acquisição do dominio.

$\left.4 .^{\circ}\right)$ - Os terrenos urbanos, não se incluem nas terras devolutas. Aquelles constituem as povoações de mais de 1.000 almas, delimitadas pelo circulo que tenha um raio de 6 kilometros a contar da praça central. (Leis citadas).

$5 .^{\circ}$ ) - Os terrenos urbanos, pelo direito civil de todos os tempos e pelo direito consuetudinario, pertencem ás pessoas naturaes e ás pessoas juridicas de direito privado (Cod. Civ. arts. 2 e 16), ou ás pessoas juridicąs de direito publico interno, União, Estados ou Municipios, (Cod. art. 14), que possuirem continua e pacificamente, com justo titulo e boa fé, durante dez annos entre presentes e vinte annos entre ausentes; e que possuirem sem titulos nem boa fé durante trinta annos. (Cod. arts. 163, $530 \mathrm{n}$. III e 550-553, e boa jurisprudencia do Trib. de S. Paulo nos Accordams de 9 de Fev. de 1927, posterior ao Codigo Civil, e de 26 de Fev. de 1914, na "Rev. dos Trib." vol. 21, pag. 71 e vol. 13, pag. 85).

$\left.6 .^{\circ}\right)$ - E' prova decisiva da boa fé dos particulares possuidores, o facto de lhes serem cobrados impostos relativos ao immovel possuido, o que demonstra a ausencia, a renuncia e o abandono da posse por parte dos poderes publicos;

$\left.7 .^{\circ}\right)$ - As terras devolutas, que foram cedidas pelo Estado aos Municipios, começam na adjacencia e para fóra da 
linha perimetrica de cada povoação"de mais de mil almas, como vimos no numero $2 .^{\circ}$, e terminam onde encontrarem terras pertencentes a particulares, ou a outros municipios.

8..$^{\circ}$ - Se, desse modo, o Estado não tem mais terras devolutas no seu dominio, (alem das que já possuir e das que reservou expressamente nas leis) é porque as transmittiu aos municipios. Estes, porem, terão perdido, por commisso; as terras não demarcadas na fórma e no praso do art. 222 do Dec. n. 734 de 5 de Jan. de 1900.

9..$^{\circ}$ - $\mathrm{O}$ direito material do Imperio sobre terras devolutas desappareceu após a Const. Federal art. 64 que retirou taes terras do dominio da União, passando-as para o dos Estados.

O direito administrativo dos Estados e dús Municipios, que contém regras de direito material isto é, substantivo, sobre propriedade e posse, foi revogado pelo Codigo Civil, art. 1807 e outros e pela Const. Fed. art. 34, n. ${ }^{\circ} 23$. Os Estados e municipios só podem legislar sobre o modo, o momento, o preço e as formalidades administrativas da alienação ou aforamento dos seus bens. Tudo, portanto, quanto existe nessas leis, affectando direitos individuaes de posse e propriedade, é irrito e nullo.

\section{IX}

\section{HISTORICO DA FORMAÇÃO DO ART. 67 DO CODIGO CIVIL, SOBRE A ALIENABILIDADE E PRESCRIPTIBILIDAde dos BeNS PUBLICOS.}

O projecto de Clovis Bevilaqua dividia os bens publicos em tres classes:

$\left.1^{\circ}\right)$ - os de uso commum,

$2^{\circ}$ ) - os de uso especial e

$3^{\circ}$ ) - os patrimoniaes, como sempre foi no direito patrio e dos povos cultos. E dispunha no, art.

"81. - Os bens communs, emquanto conservarem esse caracter, não são alienaveis, nem sujeitos 
á usucapião: os de uso especial e os patrimoniaes podem ser alienados, de conformidade com as leis que os regulam."

Nota-se, para logo, que esse texto fallava antecipadamente em "usucapião", pondo ahi uma entidade que deveria, mais opportunamente, apparecer na Parte Especial do Codigo, quando se regulasse methodicamente o instituto do usucapião. O capitulo, onde estava o art. 81, intitulava-se: "Dos bens em relação ás pessoas" e pertencia ao livro intiulado-: "Dos bens"

Não cogitava da "extinç̧ão de direitos" ou prescripção. Só muito depois na PARTE ESPECIAL (arts 632 e 696 ) appereciam os capitulos sobre o usucapião. Portanto, não era methodico intercalar no art. 81 o usucapião.

Por essa razão, que transparece, a Commissão dos 5 Jurisconsultos, revisora do projecto, silenciosamente, substituio aquelle, pelo seguinte:

"Art. 81. - Os bens, comprehendidos nos $\S \S 1^{\circ}$ e $2^{\circ}$ do artigo antecedente, são inalienaveis, emquanto conservarem o respectivo uso especial ou commum; os do $\S 3 .^{\circ}$ podem ser alienados, na conformidade da lei."

Como se vê, a nova redaç̧ão nada dispoz sobre usucapião, que passou, portanto, a ser regido pelos principios consignados na parte especial do Codigo, os quaes não isentam os bens publicos do usucapião.

Do exposto não é possivel deduzir que a Commissão Revisora quiz, tacitamente, estabelecer a profundissima innovação da imprescriptibilidade dos bens publicos patrimoniaes, isentando-os das regras geraes sobre o usucapião, e assim destoando de todos os codigos, e do nosso direito anterior, que nenhum inconveniente apresentava.

$\mathrm{E}^{\prime}$ inadmissivel que, sem uma palavra de justificação, aquelles cinco jurisconsultos adoptassem essa grande novidade, por meio de um enigma...... 
Enviado o projecto Revisto á Camara dos Deputados, o Relator dessa parte, que fomos nós, nada propoz nesse particular. ("Trabalhos da Camara," 1902, Vol,3 pg 24-43).

Mas, no seio da commissão dos 21, sobrevieram modificações de methodo e de fórma no Capitulo, determinando a emenda constante do meu segundo parecer, de 21 de Out. de 1901, publicado no Vol. $4^{\circ}$ dos "Trabalhos da Camara" edição de 1902, pag. $172-2$ a 172-28, e nos " "Trabalhos de Elaboração", edic. de 1919, Vol. $3^{\circ}$. pag. 345 , dizendo:

- Art. 81. - Os bens de que trata o artigo antecedente perderão a inalienabilidade, que lhes é peculiar, nos casos e pela fórma que forem decretados por leis dos poderes competentes. (assignado) Azevedo Marques, relator"

Assim redigi considerando como verdade que: $1^{\circ}-\mathrm{Em}$ regra, todos os bens publicos não são, livremente, discrecionariamente, alienaveis pelas pessoas naturaes que os possuem e administram.

Os Chefes de Estado, os Ministros, os Chefes de Repartições, quaesquer funccionarios, não podem alienar bens publicos sem previa autorisação legislativa, precisamente como accontece em relação aos bens particulares dos incapazes, bens estes que só mediante autorisações competentes podem ser alienados.

$2^{\circ}$ ) - Excepcionalmente, porem,todos os bens publicos, como atraz demonstramos com a doutrina e a pratica, podem ser alienados, desde que a lei o autorise, exactamente como accontece com os bens particulares dos incapazes cuja alienação depende de alvarás de poder judiciario. A phrase: "que lhes é peculiar" tem essa significação. A minha redacção, pois, não innovou o principio tradicional, nem os projectos Bevilaqua e o Revisto.

Si este ultimo e a minha emenda não repetiram do projecto Bevilaqua a phrase: "nem sujeitos á usucapião", foi pelo unico motivo de ser inoportuna, porque nesse capitulo não se 
tratava de estabelecer regras sobre a perda, ou extincção do dominio, assumpto este que tinha mais tarde o seu logar adequado. Remettido assim o projecto ao Senado, alli, Ruy Barbosa, no celebre parecer, que elle intitulou: "Sobre a redação, modificou ligeiramente a fórma que ficou até hoje, como está, no art. 67 do codigo.

Nada mais houve no parlamento sobre isso. Nenhuma discussão, nem uma palavra, que autorise a affirmação gratuita de serem imprescriptiveis os bens publicos patrimoniaes, o que constituria uma verdadeira monstrubsidade na historia do direito civilisado.

Podemos agora inquirir: - Onde está no Codigo o principio regulador do usucapião dos bens publicos? E' facil a solução. Está na Parte Especial Titulo II - Da Propriedade, Secção IV - Do Usucapião. arts, $550-553$ para os immoveis e $618-619$ para os moveis. E' ahi, sem a menor duvida, que se localisaram os preceitos civis que regem o instituo da prescripção de todos os bens, particulares e publicos. O Codigo não distingue, nem poderia distinguir, para esse effeito, os bens publicos dos particulares. E desde que não distinguio expressamente, é forçoso applicar aos bens publicos as regras seguintes:

Art. 550. - Aquelle que, por 30 annos, sem interrupção, sem opposição, possuir como seu Um Immovel acquirir-lhe-á o dominio.

Art. 618. - Adquirirá o dominio da Coisa Movel o que a possuir como sua, sem interrupçĩo nem opposição, durante 3 annos"

Qual é o IMMOVEL? Qual a coisa MOVEL? Quaesquer e todos, pertençam a quem pertencer. Portanto, as pessoas particulares, como as pessoas juridicas de direito publico inteno ( Estados, União e Municipios), adquirem por usucapião, e perdem por usucapião. Assim é em todos os codigos dos povos cultos.

Não contraria o exposto o principio de que os bens de uso commum do povo são imprescriptiveis porque a razão dessa imprescriptibilidade não decorre de uma expressa disposição 
legal, que não existe; mas sim e somente da propria natureza desses bens (mares, rios, estradas, ruas e praças), visto como é impossivel, materialmente, possuil-os como seus, sem interrupção nem opposição, durante 30 annos. Não é siquer sensato applicar-lhes as regras do usucapião, porque escapam á posse individual.

Em summa, do historico do art. 67 do nosso codigo, e do senso juridico resulta que os bens publicos patrimoniaes continuam sujeitos ao usucapião na systematica do Codigo Brasileiro. Ao contrario, teriamos um desastre nacional e seria urgente reformar essa parte do codigo.

S. Paulo, Julho, 1927.

9. M. de $\mathcal{A l z e v e d o}_{\text {Marques }}$ 